\title{
Current Status of ISO/TC202 - Microbeam Analysis
}

Patrick Camus ${ }^{1}$, Douglas Meier ${ }^{2}$ and Ryna Marinenko ${ }^{3}$

${ }^{1 .}$ EDAX Inc., A Division of Ametek, 91 McKee Place, Mahwah, NJ

2. McCrone Associates, Inc., 850 Pasquinelli Drive, Westmont, IL

${ }^{3 .}$ NIST; MS 8371, 100 Bureau Dr., Gaithersburg, MD

"We're ISO, the International Organization for Standardization. We develop and publish International Standards."

In the 23 years that TC202 has been in existence 18 international standards have been published and maintained by ISO/TC202 on the topic of Microbeam Analysis [1,2]. The scope is to provide some level of standardization to those working in the field of microbeam analysis such as measurement techniques, parameters, procedural methods, reference materials, etc. using electrons as an incident beam and electrons and/or photons as the detection signal. The purpose, primarily, is to analyze the compositional and structural characteristics of solid materials. The volume of analysis will generally involve a depth, at most of up to 10 micrometers and a surface area less than 100 square micrometers.

TC202 has 4 sub-committees (SC): Terminology, Electron probe microanalysis, Analytical electron microscopy, and Scanning electron microscopy. This TC202 is currently working very closely with TC24-Particle Characterization, TC201-Surface Chemical Analysis and TC229-Nanotechnologies.

There are currently 11 participating (voting) national member bodies and 12 observing (non-voting) national member bodies.

Participating Nation (Organization)

- China (SAC)

- Germany (DIN)

- Iran, Islamic Republic of (ISIRI)

- Japan (JISC)

- $\quad$ Korea, Republic of (KATS)

- Netherlands (NEN)

- Russian Federation (GOST R)

- Sweden (SIS)

- Uganda (UNBS)

- United Kingdom (BSI)

- United States (ANSI)

\section{Observing Nation (Organization)}

- Austria (ASI)

- Cuba (NC)

- Czech Republic (UNMZ)

- Egypt (EOS)

- Finland (SFS)

- France (AFNOR)

- India (BIS)

- Italy (UNI)

- Morocco (IMANOR)

- Poland (PKN)

- Romania (ASRO)

- $\quad$ Turkey (TSE)

The participants in this TC and its SC's strive to create standards which will benefit users in selecting or using microbeam instruments. The ability of this TC to continue to provide standards to the field depends on a variety of input from the microbeam analysis community. Primarily we are looking for volunteers to work on the TC or on one of its SC's. This involves making decisions on proposals, renewals on older standards, offering technical and editorial input on 
draft standards, and sometimes attendance at an annual meeting maybe at an international location. Secondarily, the committees are looking for volunteers to submit proposals or to act as national member body experts during the review of proposals and renewals.

"Why should I participate?", you may ask.

- To use your expertise to improve the work of others in the field by standardizing the operating procedures and reference materials.

- To create standard procedures to increase the quality of operators' work, increasing the stature of the technique and the reputation of everyone in the field.

- To develop standard specifications and standard methods that benefit instrument operators and consumers of microanalytical data and analysis

- To encourage manufacturers to adopt higher quality and meaningful specifications

- To encourage industry to implement consistent testing and reporting

If anyone is interested in helping guide the direction of microbeam analysis standards, please contact your national member body representative.

The presentation will detail the TC202 organization and national sponsors, and the current and proposed standards.

\section{References:}

[1]http://www.iso.org/iso/home/search.htm?qt=microbeam\&published=on\&active tab=standard $\underline{\text { s\&sort_by=rel or }}$ http://www.iso.org/iso/home/store/catalogue tc/catalogue tc browse.htm?commid=54674 [2]http://www.iso.org/iso/home/standards_development/list_of_iso_technical_committees/iso_te chnical_committee.htm?commid=54674 